\title{
The Thinking and exploration on the Foreign Language Linguistic Studies in China
}

\author{
Xuping Liu \\ Zhejiang Institute of Economics and Trade, Hangzhou, Zhejiang, 310000, China
}

Keywords: Foreign language, linguistic, research, think, explore

\begin{abstract}
In terms of foreign language linguistic study, it has a wide range and many branches. Foreign language linguistic is a strong theoretical researching course including applied linguistics, individual linguistics and general linguistics. The disciplines of these branches have played an active role in promoting the overall study of foreign language linguistics. Theoretical knowledge of foreign language linguistics can promote foreign languages in practice and development. With the society development, foreign language research perspectives and researchers' ideas are also innovated along with their efforts. This article is a general review and thinking on the foreign language linguistic studies in China.
\end{abstract}

\section{Introduction}

Endowed with rich contents and diverse forms, foreign linguistics develops well among the contemporary academic theory research disciplines, and the significance of different foreign linguistics researches varies on different levels in practice. More than an exploration of linguistic theories, researches on foreign language linguistics also represent a theoretical extension for better application of foreign languages, and can enable Chinese researchers to understand foreign languages on a more comprehensive and systematic basis. Although the current domestic researches on foreign language linguistics are not comprehensive and specific enough, a thoroughness of such researches can be expected via the persistent exploration of researchers.

\section{The classification of foreign language linguistic studies}

The theoretical study of foreign language linguistics can be divided into theoretical linguistics, applied linguistics, general linguistics, individual linguistics and applied linguistics. In other words, the applied linguistics is established on the basis of theoretical linguistics. An analysis is made on the research features of these two foreign language linguistics disciplines below.

\subsection{Applied linguistics}

Bearing comprehensiveness and wideness in the research scope of applied linguistics, this discipline refers to the practical exploration based on theoretical linguistic researches, or the answers to issues emerging in foreign language linguistics researches. Its main purpose is to solve the issue of insufficiently close association between theories and practices of foreign language linguistics, and to integrate theoretical research achievements into practical applications. Applied linguistics can be distinguished in narrow sense and broad sense: the former refers to a comprehensive discipline covering foreign language teaching and researches; the latter refers to understandings of historical backgrounds and cultural knowledge related to foreign languages, thus to help improve learner's comprehension ability of foreign language linguistics and to better apply the language in real life and daily oral communication. As an integration of a foreign language into other disciplines, applied linguistics can include linguistics in the dimensions of: finance, culture, anthropology, etc.; through learning and extended applications of these disciplines, an obstacle-free communication with foreigners can be guaranteed in trans-cultural exchange, thus to realize the goal of foreign language linguistics studies. 


\subsection{Theoretical linguistics.}

Theoretical linguistics is researching on foreign language study theory in a broad sense, it includes foreign language pronunciation, vocabulary, grammar and sentence patterns etc. In a narrow sense, it refers to research the theory of linguistics and language knowledge in modern foreign language linguistics theories. In the study of theoretical linguistics, we can study deeply in pronunciation, words, sentence patterns, semantics, grammar and integrated these research results in the end. During the process of theoretical linguistics studies, the researchers need to master certain basic knowledge and skills, to form a scientific theoretical system about the contents relevant of language, and to accumulate the basic knowledge of theoretical linguistics.

\subsection{Individual linguistics and general linguistics.}

Individual linguistics is a linguistic research field in foreign language linguistics which refers to the research of another country's language. Each country has an unique linguistic culture with characteristics of the county. So individual linguistics takes the language as the study object and is the foundation of foreign linguistic studies. While the research scope of general linguistics is the opposite of individual linguistics. General linguistics research focuses on language theory study by exploring different languages to be arranged in different countries and in different contexts.

\section{The goals of foreign language linguistics studies in China}

There are two kinds of studies in linguistics in China, including Chinese linguistics and foreign language linguistics. However, linguistics is just foreign language linguistics in a foreigner's point of view. In fact, this classification method does not conform to the actual development direction. The aims of this study in foreign language linguistics include: to make the Chinese understand foreign language characteristics and historical culture and to help international exchanges to achieve the integration of Chinese and Western culture; to promote the ability to research and explore their native language for Chinese, and to master the differences between foreign and Chinese linguistics. This research model will improve the efficiency of study in foreign language linguistics and find more effective research methods. Language researchers should also study Chinese language in the process of foreign language linguistics study.

\section{The current situation of foreign language linguistics studies in China}

A series of problems appeared in the research process due to foreign language linguistics studies only make progress in recent decades. These problems hinder and restrict the development and application of foreign language linguistics. The current situation of foreign language linguistics will be analyzed and judged efficiently below.

\subsection{The linguistics studies patterns}

Many Chinese students read all day but have poor practical ability because they just focus on the theoretical research scope. In foreign language linguistics research, they overvalue theoretical linguistics and despise applied linguistics study. However, along with the national system of educational research continuously, exploring and updating foreign language linguistics and highlight foreign language talents make China's foreign language linguistics gradually transformed into application of applied linguistics study. Transmitting foreign advanced culture and technology to Chinese through various forms of translation so that Chinese and foreign cultures will promote to some degree. Foreign language linguistics research in China is also developing and improving and contributes to the application and practice of foreign language. In addition, when Chinese language researchers study foreign language linguistics contents, they also study western traditional culture and customs, and use the research results in the linguistics study scope. It is easier to make research results of foreign language linguistics accepted by many scholars. 


\subsection{The wide range of linguistics studies}

The foreign language linguistics studies in China are making a big progress overall from the current state of development, both in theoretical linguistics studies and applied linguistics studies. Chinese language researchers can integrate theoretical linguistics and applied linguistics effectively in their studies. Nowadays, many universities in China have start up the language study in English, French, Russian and other languages. Foreign language linguistics research in China is leveling up through the application mode which professional talents study how to transform theory into practical. This can be reflected in Chinese literature and periodicals. A relative professional research system has been established in China in foreign language linguistics studies fields. And Chinese research content and research results are equalized by other countries. Chinese scholars have studied foreign languages corresponding with the foreign cultures, histories, customs which laid the foundation for the development of subtle foreign language linguistics.

\section{The trend on foreign language linguistics studies in China}

We need to constantly improve the plan and content of the research, pay attention to the integration of language and foreign culture and various factors to achieve a fairly high level of foreign language linguistics studies. It will also help to the development of foreign language linguistics.

\subsection{Strengthen cultural cultivation}

There is "two skins" phenomenon when Chinese linguistics research scholars study foreign language linguistics. That means our academic environment have mutually exclusive serious phenomenon. It has no contact between foreign language and Chinese language. When meeting the situation translated foreign language for a normal researcher, he or she often translate according to the way such as grammar or special sentence patterns. But it does not reflect the unique localization features of language, only translate stiffly. This phenomenon indicates that linguistics researchers not only study language itself, but also analysis the cultural background of the language research. In the end, combining with a nation history and customs to translate foreign language into what the nations can accept. In the linguistic studies of all over the world, Chinese language is the most complex, which is closely related to the long history and profound culture of China. But the British history and culture are simple and pure whose language environment is relatively simple and the grammatical structure is clear. So it is convenient to research. In the study of linguistics, language scholars in China not only need to study the culture behind Chinese, but also need to study the culture in various ethnic groups and region. From the linguistic research currently, from the sound to shape is difficult and emphasis on the foreign language study based on Chinese language platform. Therefore, Chinese language scholars should continue to explore the Chinese language culture, and to complete the study of foreign language linguistics on this basis.

\subsection{Value linguistics study in universities}

Universities are the places to cultivate students' professional skills and study comprehensively. The linguistic researchers are the core of the teachers to teach students the knowledge of the linguistics in universities. Foreign language linguistics researchers in universities only to make a breakthrough in the research content and methods which can promote the foreign language teaching, so that students will have a breakthrough of the foreign language in theoretical knowledge and practical skills. Foreign language linguistics researchers in universities should actively carry out activities and training about foreign language in order to make foreign language widely used in students' daily learning, and to deepen students' attention to the foreign language. Therefore, all the students can take the initiative to foreign language linguistics. Besides, college linguistics teachers should often communicate with foreign linguists in the society, they should have a certain understanding of foreign language linguistics achievement, and constantly innovate the mode of university teachers educate and research. College education is irreplaceable and has played a pivotal 
role for students. So teachers in universities who are teaching foreign language knowledge should pay more attention to the combination of theoretical linguistics and applied linguistics. The universities which have a certain economic base and the ability can also ask Chinese or foreign language linguistic researchers to teach the linguistics knowledge and skills. And to popularize modern Chinese language study through the interactive teaching and experience teaching. For the students who are poor in foreign language linguistics knowledge have regular interaction and cooperative learning with linguistics researchers via the network client and through their daily experience to expand the study of foreign language linguistics. Finally, to achieve the overall level of foreign language as well as promote the role and purpose of foreign language linguistics in college education.

\subsection{Stress on the spread of culture.}

With the closer and more frequent exchanges among the countries in the world, language is usually acted as the carrier of the cultural and historical backgrounds in the international exchanges, so language becomes the bridge of cultural communication. Learning and studying foreign languages not only help communicate with people in other countries, but also help promote the friendly relations at home and abroad.

Linguistic culture also plays an important role in the direction of linguistics research in the future. We should perfect the application of foreign language linguistics in international communication based on the cultural theory and linguistics for translation. The in-depth research on the foreign language has promoted national language develop and spread to the western countries. It helps introduce the new knowledge and experience in linguistics from other countries to China. And there are some significance and effect for the development of the foreign exchanges. For the purpose of better applying the foreign languages and making the integration of Chinese and Western culture, it is necessary to do research and analysis on the foreign linguistics with a purpose, make clear the cultural knowledge behind foreign linguistics, and have an all-wave understanding of the grammar environment and use environment of the foreign linguistics.

\section{Summary}

In summary, this article makes the research and analysis on the thinking and exploration of the foreign language linguistics from four aspects. The foreign language linguistic study lays the groundwork to the communication among China and other countries in the future; it also has a special significance and influence for linguistic development. In the process of research, scholars should constantly develop the characteristics and theoretical contents of the foreign languages, and effectively combine the linguistics studies in China with the studies in other countries.

\section{References}

[1] Lixia Zhang. The application research of reflective teaching in the reform of Foreign language linguistics courses [J]. Asia-Pacific Journal of Education, 2016 (35): 238+237.

[2] Jianshe Zhang, Guidong Li, Xiaohua Ren. The $15^{\text {th }}$ International Association for Languages and Intercultural Communication Had Successfully held in Peking University [J]. linguistics research, 2016 (02): 233-235.

[3] Yi Sun. Contemporary science of metaphor in China (1994 - 2013) -- a literature metrology study based on CSSCI foreign language journals. [J]. Journal of Xi'an International Studies University, 2015,23 (03): 17-22.

[4] You Ma. On the effective strategy of the discipline construction in Foreign Languages College -taking Foreign language linguistics and applied linguistics as an example, [J]. New West (Late. Theoretical Version), 2015 (15): 141-142.

[5] Pei Wang. The Thinking and exploration on the Foreign language linguistic research [J]. the exam weekly, 2017 (70): 67+82. 